wisdom which confides the most in and meddles the least with those men who devote so great a portion of their time and experience, with much zealous care and anxiety, to the relief of suffering and disease in every shape and form.

Amputation of the thigh; antero-posterior flaps. - $\mathrm{B}-$, aged twenty-four. Gonorrhœal synovitis of the knee, of three intemperate habits. The patient had been treated at intervals before admission; under treatment in the Dreadnought four months; ulceration and suppuration in the joint. Chloroform was administered; wound dressed with dry cotton; union by first intention on the third day. The patient was allowed to get up on the thirteenth day.

Amputation of the thigh; antero-posterior flaps. $-\mathrm{N}-$. aged twenty-one. Compound fracture of the right leg, with severe contusion, and laceration of the soft parts, followed by diffuse inflammation, and death of the cellular tissue, relieved for a time by free incisions, when a low form of suppuration occurred, extending into the knee-joint. Chloroform was given; hectic and night-sweats; the severe pain, anxious countenance, loss of sleep, \&c., subsided with the operation. The man made a slow but satisfactory recovery.

Amputation of the thigh; circular operation. - S- - aged nineteen. Recent injury to the knee-joint by a fall, followed by inflammation and deep-seated suppuration around the joint. A free incision was made about five days afterwards, which admitted the finger into the popliteal space, when the lower and back part of the femur was found diseased. There had been much pain and constitutional disturbance prior to the operation. Chloroform was given. Convalescence very satisfactory.

Amputation of the leg; circular operation. - $\mathrm{H}_{-}$, aged thirty-nine. Disease of the lower end of the tibia, affecting the ankle-joint, apparently syphilitic. A small sequestrum was discovered in the articular extremity; the tarsal bones not affected. Amputation at the joint was first contemplated; but when the man was under the influence of chloroform, it was then more satisfactorily ascertained that the limits of the disease would not admit of this proceeding. The case did well.

Amputation of the leg; circular operation. - J-_, aged twenty. Frost-bite; did well until the evening of the sixth day, when he became violently delirious; in fact, what appeared to be a decided attack of traumatic delirium, accom. panied with the symptoms of pyæmia. Died on the fourth day following. Chloroform was administered. When delirium came on the patient refused food, stimulants, and medicine, under the impression that people were going to kill him. In a former case of traumatic delirium following amputation of the thigh, in a man who had been much addicted to drinking, I found opium and stimulants most beneficial.

Amputation at the ankle-joint; Pirogoff's method. $-\mathrm{N}-$ aged eighteen. Scrofulous caries of the joint. Chloroform was given. Particulars previously published. There was very satisfactory union at the end of twelve days.

A mputation of the foot: Hey's method. - - T__ , aged twenty five. This was an old frost-bite. Instead of disarticulating in this case, the saw was run straight through, just in front of the tarso-metatarsal articulation, the patient being under the influence of chloroform. I have never seen any objection to sawing through the bones of the foot in amputations at that part; but am rather inclined to prefer it as being more expe. ditious, and attended with less risk.

Amputation of the forearn; flaps. - $\mathrm{Y}-$ _, aged forty-five. The subject of severe thecal abscess, extending into the hand. He did well until he was allowed to go on liberty, when he over-exerted himself, which was followed by an attack of erysipelatous inflammation, extending into the wrist-joint. He was discharged within three weeks after the operation.

Amputation of the forearm; flaps. - $\mathrm{R}$-.., aged sixteen. Compound comminuted fracture from machinery. Immediate amputation. He was allowed to get out of bed on the sixth day, and left the hospital on the fourteenth.

Amputation of the upper arm.-C-_-, aged sixteen, was admitted with acute necrosis of the ulna, extending along its whole length, and lastly affecting the elbow and lower extremity of the humerus. Chloroform was given. This patient suffered very great pain, and was much reduced by nightsweats and loss of sleep. Was convalescent in about two weeks after the operation.

Amputation at the shoulder-joint.-B__, aged thirteen. Destruction of the whole arm by machinery; and the soft parts 362 were so high up and extensively destroyed as to render it a matter of some difficulty to save covering for a flap. Chloro. form was administered. Great care was taken to cut out all damaged tissue, and to cleanse the parts smeared with dirty oil. Wound left open for a few hours. On the eighth day, the boy was allowed to get up.

Excision of elbow.-B_, aged twenty-five. In this case there was five inches of bone removed including the three which enter into the formation of the joint. The man had very good use in the false joint. Recorded in the "Transactions" of the Royal Medico-Chirurgical Society.

Removal of large tumour.- J-, aged twenty-eight. A malignant growth on the side of the head corresponding to the left temporal region, measuring antero-posteriorly nine inches; vertically, seven inches; resembling in size and shape a fullgrown fotal head. It appeared a few weeks after a severe injury, and was marked by a very rapid increase in size, but unaccompanied with pain or constitutional disturbance. The attachments were, to the coronoid process of the inferior maxilla, and deeply in the pterygo-maxillary fossa. The malar bone, with the zygomatic arch, were considerably protruded; whilst the squamous portion of the temporal and the large wing of the sphenoid were thrust inwards, and partly absorbed by pressure. The bleeding during the operation was very profuse. Had an attack of erysipelas, which passed off in about nine days. The wound then rapidly healed, and in fourteen days the man was allowed to go on liberty, but did not return, and in six weeks was admitted into the Middlesex Hospital, under Mr. Shaw, by whom a second operation was performed. The man sank in a few weeks from exhaustion.

Trephining the skull._-S__, aged twenty-four. Fracture, without any external wound, and no perceptible depression. Compression from extravasated blood between the dura mater and bone; a clot was found as large as half an orange. The man was comatose when admitted, which was immediately relieved by the operation. This most creditable case was performed by $\mathrm{Mr}$. Croft, the assistant-surgeon, during my absence, and afterwards reported by himself. The man left the hospital at the end of about two months, in a very satisfactory condition.

Three large tumours from the legs. - B —, aged forty-five. These were dense fibrous tumours, about the size of a man's fist, two upon the left leg; the upper one situated on, and closely attached to, the patella, connected with the lower one, which occupied the upper part of the front of the leg and ligamentum patellæ, by a thick fibrous band. The third tumour was on the right leg, a little below the knee. The incision to. remove these tumours was about ten inches in a straight line, and with three lateral incisions, a large raw surface was exposed. The patient had rather severe symptoms, which were more dependent upon the shock, but he eventually did well.

[Note.-In the year 1858.59, the operations have been com. paratively few, but these have done well; and the sanitary condition of the hospital continues to be satisfactory.]

March, 1859 .

\section{DESCRIPTION OF THE}

\section{OVARIAN OR ABDOMINAL SOUND :}

A NEW INSTRUMENT FOR THE EXAMINATION OF SUSPECTED OVARIAN CYSTIO TUMOURS, ETC.

BY GRAILY HEWITT, M.D., L.R.C.P.,

PHYSICIAN TO THE BRITISH LYING-IN HOSPITAI AND TO THE SAMARITAN HOSPITAL.

ThIs instrument, lately exhibited at a meeting of the Obstetrical Society of London, is contrived for the purpose of carrying out an internal examination of abdominal fluctuating tumours suspected to be ovarian, with the view of rendering the diagnosis of the nature, position, and composition of such tumours more certain.

The apparatus necessary consists of an ordinary canula and trocar (B), and a probe fourteen inches or more in length, graduated in inches, rounded at its extremity, and composed of a flexible metal (A). In the shoulder of the canula is fixed a diaphragm of indiarubber $(a)$, in the centre of which is a perforation, large enough to allow the trocar or the sound to pass, 


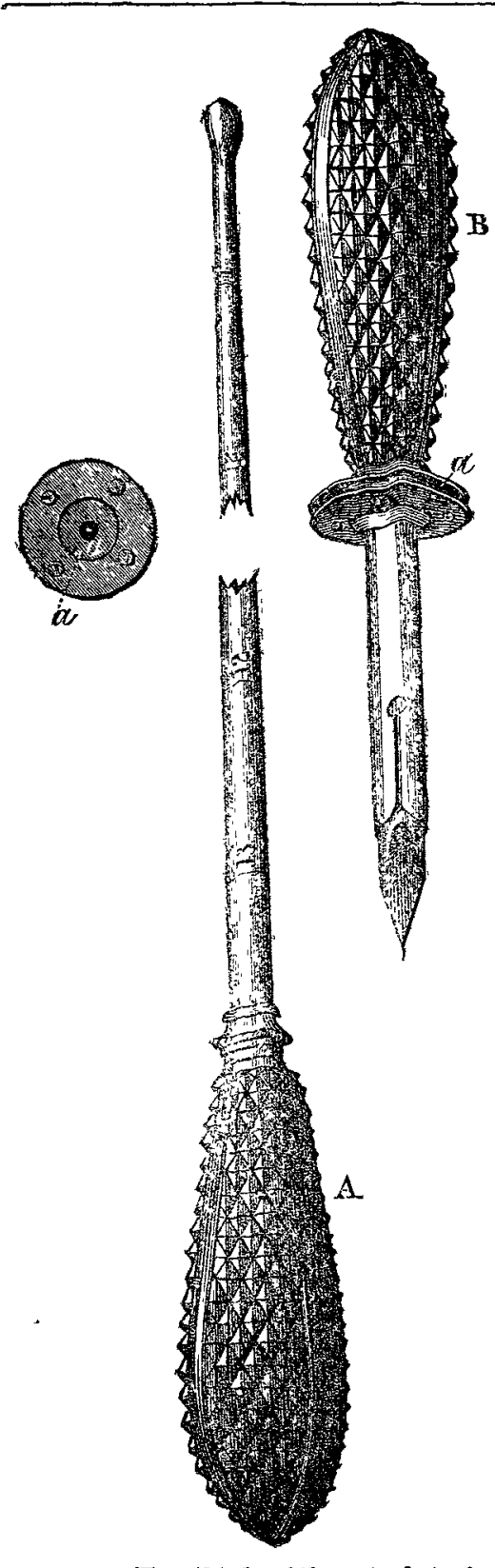

but grasping the sound so tightly as to prevent escape of fluid from the cavity into which it is in. troduced.

The trocar and canula are thrust in to the tumour, as in the operation of paracentesis; the trocar is withdrawn, and the sound introduced in its place. 'I'he observer is now in a position leisurely, carefilly, and conveniently to probe, by means of the sound, the whole of the interior of the abdominal cavity or cyst, and no fluid escapes during this examination.

Combined with vaginal and other examinations, the sound offers the means of establishing a certainty of diagnosis, in the kind of cases for which it is intended, which was before difficult of attainment. In cases of ascites mistaken for ovarian disease, the use of the sound would enable the observer to correct his error. In respect to the kind of operation, if any, proposed to be undertaken for the relief of ovarian disease, the use of the sound would give information as to its simple or compound cha. racter, which might materially influence the decision about to be made. Many other advantages obtainable by its use will readily suggest themselves, After the sound has been withdrawn, the whole or a part of the contents of the cyst or cavity may be allowed to escape.

(Two-thirds of the actual size.)

The sound was lately used by myself in the case of a patient ander the care of Mr. S. Wells. The anticipations formed as to its utility have been fully verified.

Radnor-place, Hyde-park, March, 1859.

\section{REMARKABLE CASE OF OBESITY IN A HINDOO BOY AGED TWELVE YEARS.}

BY W. G. DON, M.D., ASSISTANT-SURGBON H. M. 28TH REGIMENT.

THE accompanying engraving, from a photograph, is a very good representation of a Hindoo boy, known in the streets of Bombay under the soubriquet of the "Fat Boy." As he has lately attracted considerable notice in Bombay, and as his case is a very remarkable example of perverted nutrition, I shall give a few particulars regarding him.

Shakarm, a Mahratta, aged twelve years, was born at Malwan, a village in the Concan, near Goa. His father and mother both died several years ago, and he is now a beggar, living on the bounty of the many charitable citizens of Bombay. In his second year he became very fat, and the obesity has increased with his growth, year by year, till his whole body is now encased in an immense mass of solid adipose tissue, which hangs in pendulous folds over his chest and hips, and the flexures of his limbs. He enjoys excellent health, and has a moderately good appetite, living chiefly on dhal (peas) and rice. He has no complaint whatever, except a difficulty of breathing when he subjects himself to any very rigorous exercise. His appearance is extremely odd, and he walks with difficulty, and when tired rests himself by leaning his pendulons abdomen against a wall. He is about the average height of Hindoo boys of his age, and his members are proportionately developed in every part; the genital organs, however, are not larger than those of an infant, while the testes are very small, and seem either to be uncleveloped or to have become atrophied. He has beautiful teeth and eyes, and is highly intelligent. His weight and dimensions are as follow :-

\begin{tabular}{|c|c|c|c|c|c|c|}
\hline $\begin{array}{l}\text { Weight } \\
\text { Height }\end{array}$ & $\cdots$ & $\cdots$ & $\ldots$ & & \multirow{2}{*}{\multicolumn{2}{|c|}{$\begin{array}{l}2061 \mathrm{bs} . \\
49 \frac{1}{2} \text { inches }\end{array}$}} \\
\hline $\mathrm{Cinth}$ & chest & $\ldots$ & $\cdots$ & $\ldots$ & & \\
\hline 9 & men & & $\ldots$ & $\ldots$ & 43 & 9 \\
\hline ," & t] & $\ldots$ & $\ldots$ & $\cdots$ & 27 & $"$ \\
\hline ", & & $\cdots$ & $\cdots$ & .. & $\begin{array}{l}16 \\
15 \frac{1}{9}\end{array}$ & ", \\
\hline Lengtl & & 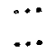 & $\cdots$ & $\cdots$ & $6 \frac{1}{2}$ & , \\
\hline
\end{tabular}

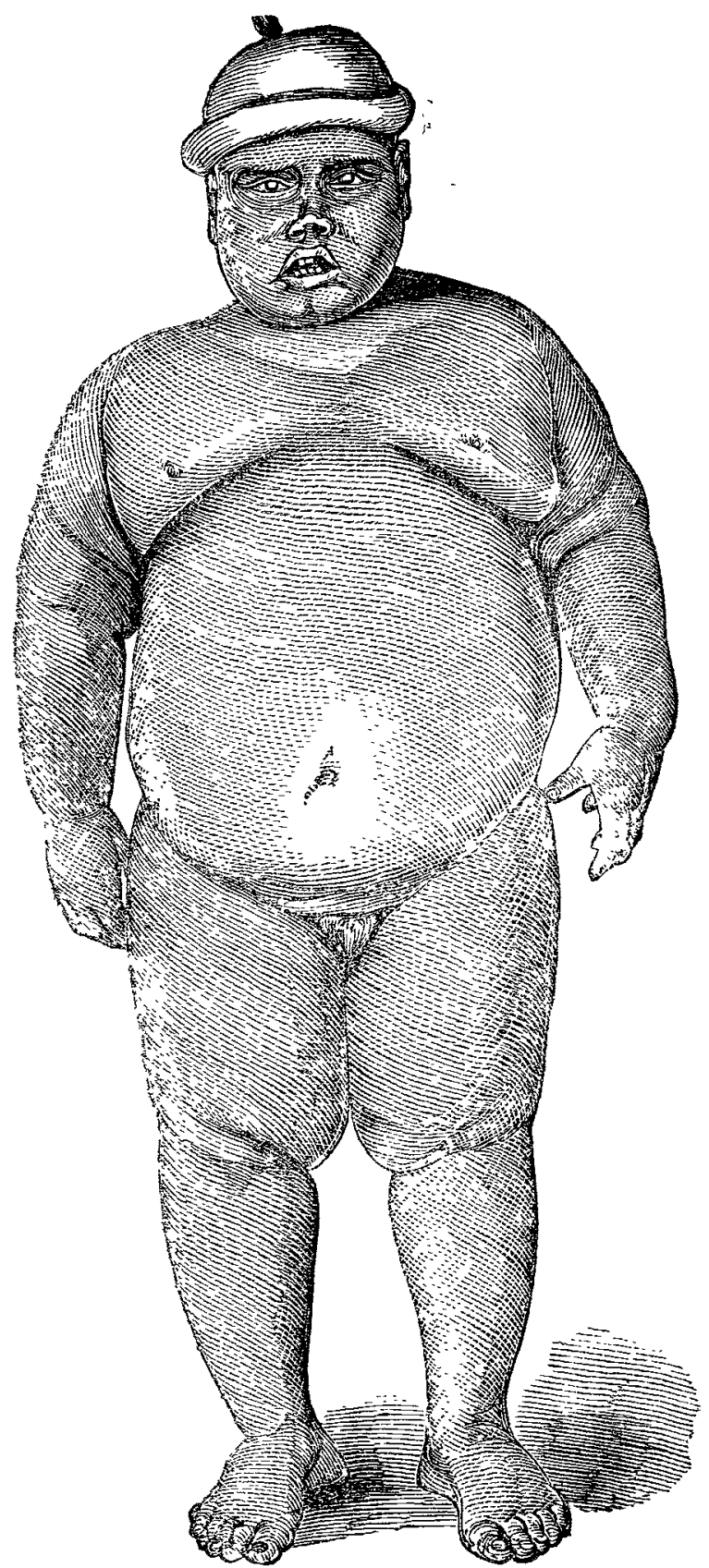

Town Barracks, Bombay, 1859.

ON A

\section{CASE OF RETROVERSION OF THE UTERUS, AND RETENTION OF URINE.}

BY R. HALI, BAK EWELI, M. D., SUBGRON TO THE ROXAL KBNT DISPBYSAEX.

THE following case presents some points of interest:-

I was sent for at nine P.M., a short time since, to see an Irishwoman, who was, of course, dying. I found her suffering 363 